\title{
Inimigos do Teatro
}

\section{Edélcio Mostaço}

Universidade do Estado de Santa Catarina - UDESC

Email: hateatro33@gmail.com

\section{Resumo}

O ensaio aborda as condenações realizadas por Tertuliano, Santo Agostinho e Rousseau ao teatro enquanto instituição.

Palavras-chave

Inimigos do Teatro. Tertuliano. Santo Agostinho. Rousseau.
Abstract

The essay focuses the censure against theatre as institution by Tertulian, St. Augustine and Rousseau.

Keywords

Theatre Enemies. Tertulian.St. Augustine, Rousseau. 
Cartago

Nem sempre o teatro despertou simpatias ou granjeou adeptos ao longo de seu transcurso histórico. Nos primórdios do cristianismo despontaram algumas vozes fazendo coro à sua condenação e, nos séculos que se seguiram, foram elas tomadas como base para diversas condenações da arte teatral e daqueles que a ela se dedicaram ao longo da história do Ocidente.

O primeiro teólogo da Igreja a invectivar contra a atividade cênica foi Quintus Septimo Florens Tertullianus, ou apenas Tertuliano (160 d.C.- 220 d.C.), no segundo século, um pagão convertido e batizado em 195 em Cartago, região do norte da África dominada pela colonização romana, provável filho de um advogado emigrado da capital, e que se tornou uma das mais intransigentes vozes a pregarem contra o paganismo na República romana. Escreveu muitas obras, divididas pelos escoliastas em apologéticas, polêmicas e disciplinares, enfeixando um sem número de abordagens que transitavam entre temas teológicos, vinculados à fé e à penitência, bem como à moral e aos comportamentos. Ao final de sua vida aderiu à seita montanista, uma vertente especialmente sensível à decadência moral, escrevendo sobre as mulheres e os espetáculos. Considerando a mulher a fonte de todo pecado, tomou-a como a raiz dos malefícios que conspurcam as almas daqueles que se deixam arrastar por suas ignomínias. Em relação aos espetáculos, Tertuliano ajuntou numa mesma rubrica o circo, os gladiadores, os jogos e o teatro, segundo ele manifestações proscritas desde as escrituras sagradas quando ali se enuncia a proibição de culto aos ídolos. Sem distinguir entre realidade e ficção, o autor ajunta o "não matarás" com o "não cometerás adultério" e o "não enganarás o próximo", deduzindo que as representações enveredavam pelos mesmos pecados verificáveis na vida real.

Em seu texto Os espetáculos (Tertuliano, 1974, p 100), classifica o recinto teatral como um "santuário de Vênus", recordando, assim, não apenas sua origem idólatra (já havia feito o mesmo em relação aos jogos e ao circo), como também um local onde impera o vício, espesso de "fumo miserável de incenso e sangue" ao qual se dirigem "dois juízes emporcalhados": o diretor de cena e o arúspice. Ambos são tomados como cultores de Baco e Vênus: o primeiro, em razão das "numerosas libações" ali praticadas e, à segunda, pela "malícia dos gestos e dos requebros, os desbragamentos sexuais" que as figuras de cena não se cansavam de cultuar para contentar uma plateia ávida de lubricidade. É preciso lembrar que Cartago dispunha, à época, de numerosos locais para a prática teatral que, a exemplo do que ocorria em Roma, comportava a tragédia e a comédia, mas, sobretudo, a atelana e o mimo.

Consideradas formas cênicas autóctones da península itálica, sobretudo da região da Etrúria, na Magna Grécia, a atelana e o mimo faziam dos histriões suas figuras mais destacadas, em apresentações que não distinguiam exatamente o que era dança e o que era pantomima declamada em modo improvisado, não deixando de apelar para o escárnio e a sátira, sendo esse o viés que caracterizava o mimo mais explicitamente. Homens e mulheres ali subiam ao palco, ao contrário do teatro grego, e frequentemente eram abordados para favores sexuais ou efetivamente exerciam a prostituição como meio de vida.

Quanto à cena, propriamente, Tertuliano caracteriza as figuras ali presentes como ídolos 
insuflados pelos demônios, a que chamam deuses. Tal passo demanda observar que, importada da cultura grega, a crença nos daimones corria livre entre as práticas religiosas mais prosaicas; mas numa versão decaída e confundida com o maniqueísmo, levando a crer que maus daimones poderiam se apossar de um indivíduo e leva-lo a cometer atos os mais abomináveis. Tais crenças irão, num breve futuro, se associarem com usos e doutrinas do judaísmo e conformarem a demonologia como entendida e configurada pela teologia cristã.

A seguir, Tertuliano faz observações sobre as emoções provocadas pelo teatro: "toda a assistência a um espetáculo provoca emoções. Onde estoura o prazer, lavra por igual a paixão, que é o sabor do prazer; e onde surge a paixão aí aparece também a emulação. E onde há emulação, aí barafustam o furor, a ira, a bílis e o desespero, que levam de vencida as regras do bom proceder. "[...] Ninguém fica de ferro frio perante a solicitação do prazer, e o afeto desregrado provoca alguma ruína”, (Tertuliano, 1974, p.106). Não é somente a cena e seus atores que são visados pelo crivo moralizador do padre, mas também seus efeitos sobre o público, preocupado com os maus hábitos que poderiam disseminar na vida cotidiana. Pois, contemplando cenas de sexo "antinatural", um homem poderia ir para casa com a imaginação fértil e o desejo açulado - e aí residia o perigo.

O circo, em seu gigantismo, insufla a ira e o furor, como bem evidencia a turba barulhenta e obcecada pelo sangue que ali faz apostas, negociando a morte seja de cristãos seja de gladiadores. No teatro, a sedução maior "vem cozida com a espurcícia que escorre dos gestos dos atores nas atelanas, que desprezam todo respeito e pudor pelo outro sexo e se en- tregam à gesticulação efeminada", bem como conduzem à apreciação das deformidades dos mimos, mais apropriadas aos prostíbulos. "Se se trata de tragédias e comédias inspiradoras de crimes e devassidões, inspiradoras ensanguentadas e lascivas, ímpias e desbragadas, melhor fora falar de outra coisa vil ou atroz e não falar de coisa nenhuma: nem falar se deve consentir do que é detestável fazer-se" (Tertuliano, 1974, p. 109).

Sobre os atores, o autoratesta:

os que dão e organizam os espetáculos
aos cocheiros, aos comediantes, aos
ginastas e gladiadores de quem se ca-
tivam e a quem os homens prostituem
o espírito e as mulheres os corpos,
quando por eles arrastados praticam o
que censuram, pela mesma razão por-
que os têm em grande conta, por essa
mesma ordem os abatem e degradam
e manifestamente os condenam à ig-
nomínia negando-lhes direitos cívicos,
escorraçando-os das assembleias, do
foro, do senado, da ordem equestre e
das restantes honras, ao mesmo tem-
po em que os proíbem de usar certas
insígnias (Tertuliano, 1974, p. 113).

Convém lembrar, para que o trecho acima seja inteiramente assimilado, que desde o edito de Caracala, em 212, todos os envolvidos com o teatro e os espetáculos em geral foram colocados na lei dainfâmia, ou seja, um conjunto de limitações a que estavam sujeitos - os citados direitos civis referidos por Tertuliano -, que os segregava da população restante e que muito contribuiu para manter os artistas cênicos discriminados durante quase dois mil anos. No caso da França, por exemplo, essa legislação restritiva só será abolida com a Revolução Francesa.

Não é difícil perceber nas palavras de Tertuliano a munição argumentativa utilizada ao longo da Idade Média para excomungar os 
atores e aparenta-los com cultores do demônio, indignos de serem enterrados em campos santos ou conhecerem a benção da extrema unção, uma vez que eram cultores de uma profissão não apenas pestilenta como amaldiçoada.

Tertuliano consolidou, com sua retórica altissonante e coalhada de expressões que exaltam a condenação e o expurgo, uma definitiva postura da Igreja frente aos espetáculos, ao teatro e aos atores que vai perdurar ao longo do tempo, assim como, ressuscitada aqui e ali, em momentos onde o acirramento de forças tomou a cena como a responsável pelos pecados do mundo.

O segundo padre da Igreja a voltar-se contra o teatro foi Agostinho de Hipona (354-430), no quarto século, também ele um pagão convertido ao cristianismo na mesma Cartago onde Tertuliano pontificara, autor de uma obra teológica considerada exemplar. Seu texto mais acentuadamente canônico é Cidade de Deus, onde defende os princípios de uma urbe cristã às voltas com as invasões bárbaras, em sua luta pela preservação de seus princípios morais e teológicos. Mas é em suas Confissões (Agostinho, 2010), autobiografia onde descreve sua vida desde a mais tenra infância até a velhice, onde explicita o contínuo e acidentado percurso no rumo da perfeição requerida pelo verdadeiro amor a Deus. Em sua juventude, transcorrida em Cartago e antes de sua conversão, Agostinho conheceu todos os pecados da carne e do espírito, quando "embaciava a sua pureza com o fumo infernal da luxúria" (2010, p. 45). Frequentador assíduo dos teatros da grande cidade em sua primeira juventude, ele grifa que eram "cheios de imagens das minhas misérias e de alimento próprio para o fogo das minhas paixões" (Agostinho, 2010, p.45).
Aparece anotado, inicialmente, o estranho poder do palco em fazer o homem condoer-se diante de cenas dolorosas e trágicas, reportando a função da compaixão: "o espectador anseia por sentir esse sofrimento que afinal para ele constitui um prazer. Não é isso uma loucura?", ele indaga (Agostinho, 2010, p. 45). Loucura que se mostra compulsiva, uma vez que induz à reincidência e torna o espectador acorrentado à cena como um louco que nela se compraz com o prazer do fictício: "disso provinha meu afeto pelas emoções dolorosas, só por aquelas que não me atingiam profundamente, pois não gostava de sofrer com as mesmas cenas em que a vista se deleitava" (Agostinho, 2010, p. 45). Temos aqui, portanto, uma economia libidinal transtornada por aquilo que Freud reconhecerá como histeria, um deslocamento de objeto que privilegia o fictício em detrimento do real. Se, a propósito daqueles tempos primeiros, tal diagnóstico possa soar excessivo, é preciso lembrar, desde sempre, a função exercida pelos diversos formatos de crenças quanto à satisfação de pulsões que significam ou se associam ao prazer.

Ainda que um prazer um tanto quanto mórbido, pois, prossegue o bispo de Hipona, "como acontece quando remexemos (uma ferida) com as unhas, este contato provocava em mim a inflamação do tumor, a podridão e o pus repelente". Ou seja, estamos diante da mais rematada repulsa frente à compaixão (ou catarse) que o teatro costuma inspirar, numa demonização de suas características - percebidas como maléficas - que atravessará os séculos vindouros, associando o que era tão somente um transporte emocional com a fisgada verídica promovida pelo agulhão da lascívia. Se Platão já advertira sobre esse corrosivo poder degenerescente das almas quando 
expostas à mímesis, o neoplatônico Agostinho (2010, p. 46) só fará aumentar tal repulsa: "mas isso, meu Deus, podia chamar-se vida? ".

$\mathrm{E}$, finalmente, chega-se ao trecho que enfeixa toda a condenação agostiniana à função da kátharsisteatral: "em quantas iniquidades me corrompi e a quantas curiosidades sacrílegas me entreguei, até precipitar, abandonando-vos, nos profundos abismos da infidelidade e no serviço enganador dos demônios a quem 'sacrificava' as minhas maldades!' (Agostinho, 2010, p. 46-47). A histeria do bispo converte-se, assim, num duplo açoite, um dirigido a si mesmo e outro a todos que trilharem o mesmo percurso. $\mathrm{O}$ ascetismo abriu desse modo suas veredas rumo ao futuro, não apenas condenando os prazeres como reafirmando as recomendações do estoicismo sobre a vida - submissão dos desejos à determinação dos princípios morais, a saúde da alma dependente do culto ao deus único -, ao pietismo formulado por Agostinho. Nos primórdios da cristandade Tertuliano e Agostinho municiaram com poderosos argumentos a luta contra o teatro, um terreno fértil e responsivo em seus apelos conjuntos quanto à administração da vida conduzida em estrita vigilância frente aos desvios, base ética sobre a qual a igreja reformada por Martinho Lutero, após o Renascimento, erigirá seus mais renitentes cânones.

\section{Genebra}

A Suíça alcançou sua independência em 1499 e seus quatro cantões concordaram em possuir, cada qual, sua religião própria em 1531. Genebra foi assomada pelo calvinismo a partir de 1541, após longo e profícuo trabalho de Calvino na região. A cidade transformou-se numa república, controlada por uma oligarquia religiosa cujo órgão executivo, denominado Consistório, estava encarregado de executar as leis e vigiar pela moral e os bons costumes. Dividida em distritos, uma comissão por ele designada averiguava, de casa em casa, possíveis desvios de conduta ou relaxamento de hábitos derivados da rígida doutrina criada pelo fundador. Dançar, jogar cartas, trabalhar ou divertir-se no sábado, Dia do Senhor, consistia em crime - bem como frequentar o teatro.

As ideias de Calvino foram coligidas nas Instituições da religião cristã (Calvino, 2008), francamente inspiradas pela obra de Agostinho de Hipona e pregavam que todos os homens são pecadores por natureza, amarrados ao mal e dele não podem escapar. Razão pela qual a penitência, as confissões frequentes e o estrito zelo de uma vida voltada às virtudes cristãs eram imperativos a que ninguém podia escapar, nem mesmo aqueles que, predestinados por Deus, alcançariam a vida eterna. Nascido na cidade e dela tendo se afastado em direção à França na idade adulta, Jean-Jacques Rousseau estava vivendo novamente em Genebra quando, em 1757, foi publicado, no sétimo volume da Enciclopédia, o artigo Genebra, da autoria de d'Alembert. Nele, o autor não se esquivou de louvar os excelentes relógios produzidos na cidade, o clima agradável da maior parte do ano e sua biblioteca pública, frequentada pela elegante e ilustrada burguesia da cidade. Mas reclamou que a urbe não tinha um teatro.

A resposta de Rousseau apareceu no ano seguinte e tornou-se conhecida como Carta a d'Alembert sobre os espetáculos( Rousseau, $\mathrm{s} / \mathrm{d}$ ), um dos mais vivos libelos contra o teatro jamais escrito. Em certa maneira, a missiva dirigia-se contra Voltaire, uma vez que esse 
tentara, em anos anteriores, e por diversas vezes, instituir um teatro na cidade que, como se sabe, dista poucos quilômetros da divisa com a França. No escrito, Rousseau inicia seus argumentos defendendo os princípios religiosos e morais preconizados pelo Consistório, justificando porquê não existir uma casa de espetáculos na cidade. Inicialmente, porque os espetáculos constituem uma distração, e os homens de bem não necessitam desse tipo de lazer. Em seguida, porque a atividade teatral deve procurar um prazer próprio à índole de cada povo e, o que se observa, é que cada cidade cultiva um tipo de teatro distinto, segundo suas inclinações. Dizer que o teatro é uma escola de convivência social é bastante relativo, nos argumentos do autor: "gostaria muito que me mostrassem, claramente, sem palavrório, quais os meios que o teatro poderia utilizar para causar-nos sentimentos que não possuímos e fazer com que julguemos os seres morais de modo diverso daquele que fazemos por nós mesmos" (Rousseau, s/d, p. 351).

Sua postura se adequa, desse modo, àquela mesma que João Calvino havia consagrado em suas Instituições da Religião Cristã respeito das representações em geral: "Se certamente não é lícito representar a Deus em uma forma visível, muito menos será adorar tal imagem como se fosse Deus ou adorar a Deus nela. Resta, portanto, que seja pintado ou esculpido aquilo que os olhos são capazes de ver; a majestade de Deus, que está muito acima do sentido dos olhos, não deve ser corrompida por imagens indecorosas" (2008, p. 105), delimitando assim, para qualquer criação artística, um horizonte inteiramente adstrito ao realismo e mesmo ao naturalismo da visibilidade.

A disposição álacre de Rousseau prossegue e, sobre a comédia, ele pergunta: "o que vai ver no espetáculo? Justamente o que gostaria de encontrar em todos os corações - lições de virtude para o público, do qual julga ser exceção, e pessoas que tudo imolam ao dever, enquanto dele nada se exige". E sobre a tragédia: "ouço dizer que a tragédia leva, pelo terror, à piedade. Seja, mas que piedade é essa? Uma emoção passageira e vã, que não dura mais que a ilusão que a produziu; um resto de sentimento natural, logo abafado pelas paixões; uma piedade estéril, que satisfaz com algumas lágrimas e nunca produziu o menor ato de humanidade" (Rousseau, s/d, p. 352).

Nas páginas seguintes o filósofo examina em pormenores vários textos teatrais de diferentes épocas e autores, com o intuito de averiguar suas possíveis qualidades, sempre de um ponto de vista moral, em relação à plateia. Descontente com essa amostragem textual, seu desagrado se prolonga sobre a materialidade do evento artístico, as atuações, os figurinos e os cenários, que podem acarretar a emulação dos espectadores em adotá-los em sua vida cotidiana, desequilibrando a vida simples e frugal que se desfrutava em Genebra. E isso tudo induz à corrupção, à desagregação dos valores, à dissipação de hábitos sadios e em acordo com a natureza humana: "porque tendo menos modelos, cada um tira mais de si mesmo e em tudo coloca mais de seu", [...] "porque vendo-se menos, se imagina mais e, finalmente, porque, menos instigando o tempo, se tem mais oportunidade para desenvolver e digerir as próprias ideias" (Rousseau, s/d, p. 379). Ou seja, como ele resume, uma vida simplória convém mais ao espírito gregário e favorece o devotamento à família.

Esse apego à vida simples, à transparência das relações sociais, é o vértice sobre o qual repousa a vontade geral, aquela força originá- 
ria que mantêm e sustenta o sistema político na pequena república: "a soberania não pode ser representada, pela mesma razão por que não pode ser alienada; consiste essencialmente na vontade geral e a vontade absolutamente não se representa. É ela mesma ou é outra, não há meio termo", figura no Contrato Social (Rousseau, 1978, pp. 107-108). Uma afirmação como essa contrasta, violentamente, com o regime da polis grega, o paradigma mais invocado por Rousseau para sustentar seus argumentos, ela que foi uma democracia que instituiu o teatro como um de seus mais destacados produtos artísticos e um dos pilaresde sustentação de seu regime. Na mesma linha de raciocínio, cabe destacar o desagrado do genebrino em relação ao representante e ao representado. No mesmo capítulo do Contrato Social, ele já anotara: "[...] a pessoa do último cidadão é tão sagrada e inviolável quanto a do primeiro magistrado, pois onde se encontra o representado não mais existe o representante" (Rousseau, 1978, p. 106); e, a seguir: "a ideia de representantes é moderna" (Rousseau, idem).

É contra o representante, portanto, que trabalha o discurso de Rousseau, esse mal moderno que ameaça e pode fazer ruir a instituição da soberania da pequena república; o que nos ajuda a entender até onde sua fúria contra o teatro - o próprio mesmo da representação e do representante - almeja alcançar. $\mathrm{Na}$ sequência da Carta a d"Alembert, pode-se ler: "além desses efeitos do teatro relativos às coisas representadas, há outros não menos necessários, que se referem diretamente à cena e aos personagens representantes; e é a estes que os genebrinos já citados atribuem o gosto pelo luxo, pelo adorno e pela dissipação, cuja introdução entre nós eles temem com razão"
(Rousseau, s/d, p. 377, grifo meu). Jacques Derrida (1973, p. 372) não deixou incólume tal contrafação e dispara: "o que Rousseau crítica, em última análise, não é o conteúdo do espetáculo, o sentido por ele re-presentado, embora também o critique: é a re-presentação mesma. Exatamente como na ordem política, a ameaça tem a forma do representante".

A seguir, a Carta fixa uma diferença radical entre o orador ou o pregador e o ator:

quando o orador se apresenta, é para falar e não para dar-se em espetáculo; ele representa unicamente a si mesmo, desempenha somente o seu papel, só fala em seu próprio nome" [...] "mas um ator em cena, exibindo sentimentos outros que não os seus, dizendo unicamente o que the fazem dizer, representando frequentemente um ser quimérico, destrói-se por assim dizer, anula-se em seu herói e, caso reste ainda alguma coisa dele nesse esquecimento de homem, será para servir ao divertimento dos espectadores (Rousseau, s/d, p. 395).

O que o genebrino abomina, portanto, não é apenas a dissipação moral que o teatro possa ensejar enquanto instituição fictícia, mas, sobretudo, a própria noção de representação, seja no âmbito da assembleia política, seja no âmbito da cena, incapaz de suportar aquilo que ela acarreta enquanto desdobramento, referência ou jogo. Ele emula, com outras palavras, o mesmo que Platão já condenara em sua feição filosófica e Agostinho reiterara em sua feição teológica.

Prosseguindo suas considerações sobre a profissão de ator, Rousseau é eloquente: "uma profissão na qual o indivíduo se entrega à representação a troco de dinheiro, submete-se à ignomínia e às afrontas que se adquire o direito de the fazer e, publicamente, coloca à venda a sua pessoa. Desafio qualquer homem sincero 
a dizer se, no fundo de sua alma, não sente que existe alguma coisa de servil e baixo nesse tráfico de si mesmo" (Rousseau, s/d, p. 394), fazendo eco, ainda uma vez, àquelas longínquas reprimendas encetadas por Tertuliano e Agostinho, agora refinadas, todavia, pelo crivo mais esclarecido do iluminismo. Ainda que reconheça que o ator não é um impostor, não deixa de anotar que o cultivo do hábito da impostura pode apoderar-se de seu caráter, fazendo com que "a tentação de agir mal aumenta com facilidade e impõe-se que os comediantes sejam mais virtuosos do que os outros homens, caso não sejam mais corrompidos" (Rousseau, s/d, p. 395).

A existência de espetáculos, enfim, poderia transtornar todo o cotidiano da cidade: as mulheres gostarão de apresentar suas melhores roupas, os homens perderão seu contato fraterno nas estalagens, e todos renunciarão à vida simples em torno dos círculos de amigos. Estão as pequenas repúblicas, portanto, destinadas a jamais possuírem espetáculos? Não, responde ele, uma vez que "vós mesmos dareis um espetáculo, o mais digno que ele possa iluminar"[...] - "fincai no meio de uma praça uma estaca coroada de flores, reuni aí o povo e tereis uma festa. Fazei melhor ainda; transformai os espectadores em espetáculo; tornai-os atores, fazei com que cada um se veja, se ame nos outros, a fim de que todos terminem, assim mais unidos" (Rousseau, s/d, p. 428).

Com tal solução, Rousseau faz reviver no século XVIII aquele mesmo espírito platônico que fizera de Esparta uma cidade modelo, não apenas pela frugalidade de seus hábitos de vida como, notadamente, a sisuda moralidade que nela intermediava a totalidade das relações interpessoais. $O$ estro da anti- ga mousiké ${ }^{1}$ volta aqui a fornecer adubo ao imaginário rousseauniano, uma vez que essa partilha de energias em torno de atividades coletivistas encontra na festa - e mais especificamente no baile -, todo seu potencial para manter o povo unido, disposto e robusto quando entregue às danças de convivência. Mas sua imaginação vai ainda mais longe coroando esse sonho produtivista, ao indagar: "por que, baseando-nos no modelo dos prêmios militares, não fundamos outros prêmios de ginástica, para a luta, para a corrida, para o disco e para os vários exercícios do corpo?" (Rousseau, s/d, p. 429), descortinando assim, nos primórdios da modernidade, o caminho do desporto olímpico como sólida vereda para o mens sana in corpore sano. Com muita certeza, todos os estrategos de regimes autoritários posteriores aproveitaram tais sugestões do autor de A Nova Heloísa para incluírem, junto à educação das populações, atividades desportivas que insuflassem uma coesa emulação patriótica.

Dentre outras iniciativas festivas ao ar livre, embaladas pela música e bailes, Rousseau salienta que aquelas destinadas aos jovens nubentes seriam privilegiadas, como ocasiões de saudável regozijo e sem os percalços dos encontros secretos e perigosos, uma vez que "a alegria inocente gosta de evaporar-se em pleno dia, mas o vício é amigo das trevas". E, para culminar seu espartano projeto paidético, assevera: "ofereço as festas da Lacedemônia como modelo das que desejaria existissem entre nós. Considero-as recomendáveis não somente pelo seu objeto, mas também pela sim-

1 Mousiké é o termo grego original para designar a dança, o canto e a melodia que, emanados conjuntamente, não se separavam no âmbito daquela cultura. Somente muitos séculos depois o termo passou a designar exclusivamente a melodia, e daí, tão somente a música. 
plicidade: sem pompa, sem luxo, sem aparato, tudo nelas se alimentaria, com um encanto secreto de patriotismo que as tornaria interessantes, de um certo espírito marcial conveniente a homens livres" (Rousseau, s/d, p. 435).

No juízo de Jean Starobinski (1991, p. 129), "a festa campestre, precisamente, oferece às belas almas um espetáculo que simula o retorno à inocência primeira", num claro paralelo entre esse ideal comunitário tido como natural e um estado civil anterior ao contrato social. É essa transparência nas relações humanas que a posterior divisão social vai fazer desaparecer, impondo, sob o formato de obstáculos, dificuldades muitas vezes insuperáveis aos verdadeiros encontros. Se, de um lado, o conceito de festa enquanto um espetáculo total imantou o sonho cênico de muitos homens de teatro em séculos posteriores, ele simplificou e esmaeceu, por outro, os verdadeiros contornos das interações humanas quando no contexto das relações de classe, tornando-o mera quimera.

O conjunto da obra rousseauniana apresenta farta capilaridade entre si e se institui, enquanto totalidade, num corpo doutrinal dirigido contra o absolutismo. Os termos conceituais da Carta a d'Alembert sobre os espetáculos já haviam sido evocados, em modo diverso, tanto no Contrato Social como nas novelas Emílio e A Nova Heloisa, nessa última dissipando num contexto literário e sob o álibi de personagens as máximas que, nos demais escritos, são apresentadas sem intermediação. Ao pensar o homem novo, uma síntese de nítido teor reformado frente ao decadente mundo aristocrático e católico que sustentava o ancien règime, Rousseau disseminou seus preceitos burgueses através de todos os meios que lhe foram possíveis, numa cruzada ideológica que influiu, como se sabe, sobre Kant, Hegel e Marx, além de lastrear o pensamento da totalidade do pré-romantismo alemão. Foi por esta via filosófica que seus espartanos princípios ideológicos agostinianos/calvinistas encontraram foros de ontologia ou antropologia social, ensejando uma reforma da sociedade cujas bases éticas e estéticas foram nutridas pelo mais rematado ascetismo e pela mítica pureza existencial.

A Carta a d'Alembert sobre os espetáculos, porém, deve ser tomada pelo que é: um libelo contra o teatro, não um elogio da festa. $E$ como ressaltado, na esteira de uma condenação apoiada em toda uma teologia cristã que alijou o teatro como um antro de imoralidade, de falta de verdade e território de corrupção. Evidenciando, ainda uma vez, que prazer e ascetismo se encontram não apenas em polos distais em relação à estética como irreconciliáveis, de um ponto de vista do conhecimento.

Referências

CALVINO, João. A Instituição da Religião Cristã, trad. Carlos Eduardo Oliveira et al., tomo I, São Paulo, Unesp, 2008.

DERRIDA, Jacques. Gramatologia. São Paulo, Perspectiva, 1973.

ROUSSEAU, Jean-Jacques. Carta a d' Alembert sobre os espetáculos, In: Obras Escolhidas, v. II,trad. Lourdes Santos Machado, Porto Alegre: Globo, s/d.

O contrato social. trad. Lourdes

Santos Machado,São Paulo, Abril Cultural (Os Pensadores), 1978.

TERTULIANO. A moda feminina; Os espetáculos, nota bibliográfica e introdução de António Montes Moreira; tradução e notas de Fernando Melro e João Maia, Lisboa, Verbo, 1974. 
SANTO AGOSTINHO. As Confissões, trad.

J. Oliveira Santos, A. Ambrósio de Pina, São

Paulo, Edições Folha de São Paulo, 2010.

STAROBINSKI, Jean. A transparência e o obstáculo, trad. Maria Lúcia Machado, São Paulo, Cia. das Letras, 1991.

Recebido: 25/06/2017 Aprovado: 25/08/2017 